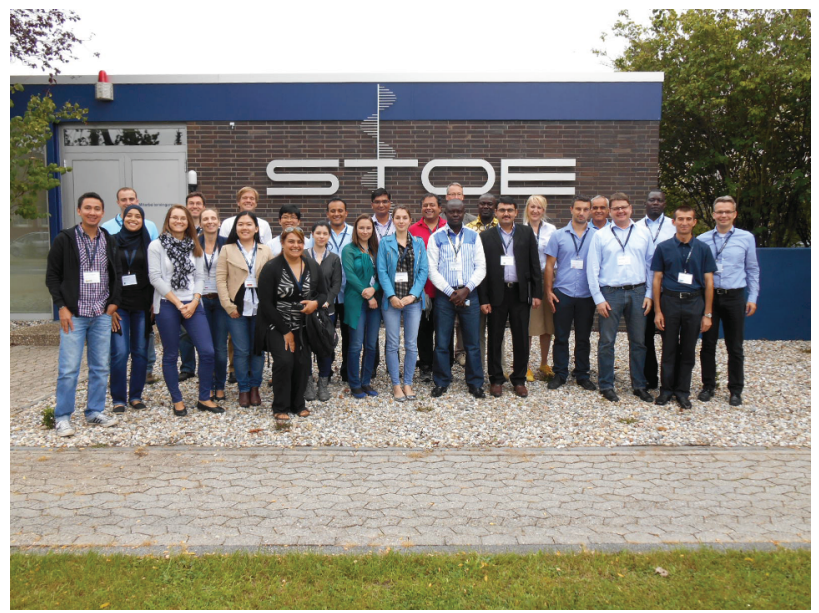

Figure 1. STOE DECTRIS Xenocs OpenFactory

Keywords: OpenFactory, IYCr 2014, Workshop, Crystallography Teaching

\section{MS48-04 The IUCr-UNESCO OpenLab} project

\author{
Michele Zema ${ }^{1,2}$, Claude Lecomte ${ }^{3}$
}

1. International Union of Crystallography, 5 Abbey Square, Chester, UK

2. Università degli Studi di Pavia, via Ferrata 1 , Pavia, Italy

3. CRM2, Université de Lorraine and CNRS, Nancy, France

email: mz@iucr.org

The worldwide nature of the UN International Year of Crystallography has provided new opportunities to develop educational activities at all levels in parts of the world where crystallography is as yet a poorly developed science, and to set in motion new initiatives in capacity building and international cooperation. In this regard and to stimulate curriculum development, the $\mathrm{IUCr}$ and UNESCO have set up the OpenLab project, a network of operational crystallographic laboratories in selected universities in Africa, Latin America and South-East Asia, as a practical start in addressing such training requirements.

During 2014 and the first months of 2015, a total of 15 OpenLabs have been organized, which provided high-level educational opportunities to local students and young professors, taking advantage of the scientific and educational expertise of the IUCr, the diplomatic and educational channels of UNESCO, and the partnership of crystallographic instrumentation manufacturers. In the OpenLabs, about 20 to 30 selected participants were taught an experimental crystallography class and were able to collect and interpret single crystal or powder $\mathrm{X}$-ray diffraction data. Some other companies also collaborated in an OpenFactory, an intensive training workshop at their European headquarters where some 20 selected early-career scientists travelled from many countries to gain hands-on experience of the latest equipment. More details and reports about these events are at http://www.iycr2014.org/openlabs.

Part of this project is closely connected with the "Crystallography in Africa" initiative of the IUCr, thanks to which crystallographic equipment has been recently installed or is being installed in some sub-Saharan African countries (e.g. Cameroon, Cote d'Ivoire, Senegal). The IUCr is willing to continue the OpenLab project and transform it into a long-term sustainable initiative in the following years. The involvement of the crystallographic community with established tradition and expertise is the key to the success of the initiative.

Keywords: IYCr2014, education, crystallography schools 